\title{
CLINICAL AND EEG ANALYSIS OF MESIAL AND LATERAL TEMPORAL LOBE SEIZURES
}

\author{
FÁBIO GALVÃO DANTAS*, ELZA MÁRCIA T. YACUBIAN**, CARMEN L. JORGE*, \\ CHRISTIANE C. PEDREIRA*, JOAQUIM F. BUENO*, ROSA M.F. VALERIO*
}

\begin{abstract}
The analysis of the temporal lobe seizures through video-EEG systems shows that they often consist of a sequence of clinical and EEG features which may suggest the localization and the lateralization of the epileptogenic lobe. We analyzed clinical and EEG features of 50 temporal lobe seizures which were separated in group 1 with 25 patients (related to mesial temporal sclerosis) and group 2 with 25 patients (other neocortical temporal lesions). Among the auras, the epigastric type was the most frequent and predominated in group 1. There were differences between the two groups, considering dystonic and tonic posturing and versive head and eye movements. Dystonic posturing was always contralateral to the ictal onset and was considered the most useful lateralizing clinical feature. Ictal speech, spitting and blinking automatisms, prolonged disorientation for place and a greatest percentage of postictal language preservation occurred in right temporal seizures. Postictal aphasia and global disorientation predominated in left temporal seizures. EEG was important for lateralizing the epileptogenic lobe, specially considering rhythmic ictal activity and postictal findings.
\end{abstract}

KEY WORDS: temporal lobe epilepsy, complex partial seizures, video-EEG.

\section{Análise clínica e eletrencefalográfica de crises epilépticas temporais de origem mesial e lateral}

RESUMO - As crises epilépticas do lobo temporal tendem a seguir uma sequência previsível de eventos clínicos e eletrencefalográficos, cuja análise, preferencialmente através de sistemas de vídeo-EEG, sugere a localização e a lateralização do lobo epileptogênico. Para este estudo, foram analisadas 50 crises epilépticas do lobo temporal, do ponto de vista clínico e eletrencefalográfico, sendo 25 relacionadas a esclerose mesial (grupo 1) e 25 a patologias neocorticais (grupo 2). Auras abdominais foram as mais frequentes, predominando no grupo 1 . Houve diferenças entre os dois grupos, quanto à instalação e duração da postura distônica, à postura tônica e à versão oculocefálica. Postura distônica unilateral foi o mais importante fenômeno clínico lateralizatório, sempre contralateral à área epileptogênica. Verbalização crítica, automatismo de cuspir, piscamento palpebral bilateral, desorientação espacial prolongada e maior percentual de preservação da linguagem no período pós-crítico foram relacionados a crises temporais direitas. Afasia pós-crítica e desorientação global, a crises temporais esquerdas. O EEG teve importante acurácia lateralizatória em ambos os grupos, especialmente quanto à atividade crítica rítmica e achados pós-críticos.

PALAVRAS-CHAVE: epilepsia do lobo temporal, crises parciais complexas, vídeo-EEG.

According to the International Classification of Epilepsies and Epileptic Syndromes ${ }^{1}$, these can be divided in partial, generalized, epilepsies and syndromes undetermined whether focal or generalized and special syndromes. Temporal lobe epilepsy (TLE) is responsible for $60 \%$ of all the partial epileptic seizures ${ }^{2}$ and it has been extensively studied clinically, electrophysiologically, and by structural and functional neuroimaging, because of its refractoriness ${ }^{3}$ and the fact that most of the

Hospital das Clinicas da Faculdade de Medicina da Universidade de São Paulo (USP): *Médico pósgraduando da Clínica Neurológica da Faculdade de Medicina da USP; **Assistente Doutora da Divisão de Clínica Neurológica do Hospital das Clínicas da Faculdade de Medicina da USP. Aceite: 20-abril-1998.

Dr. Fábio Galvão Dantas - Rua Siqueira Campos 28 - Bairro São José - 58108-540 Campina Grande PB - Brasil. 
patients $(72 \%)$ become seizure free after surgical treatment ${ }^{4}$. Temporal lobe seizures (TLS) often consist of a sequence of clinical features ${ }^{5}$, which includes: 1) aura, present at least in some seizures in almost all patients; 2) motionless stare, corresponding to a change in the attitude or behavior at the seizure onset, frequently accompanied by staring; 3) simple automatisms and contralateral motor activity - dystonia and/or paresis; and 4) complex automatisms or secondary generalization. In the past, these clinical events were described by family members, doctors or nurses and at present they have been better characterized after the videotape and, mainly, after video-EEG monitoring ${ }^{2,5-9}$. Gibbs et al. ${ }^{10}$ described an electroencephalographic pattern recorded during TLS characterized by 3$6 \mathrm{~Hz}$ rhythmic waves. More recent descriptions have demonstrated the value of scalp EEG for localization and lateralization of the epileptogenic area $(\mathrm{EA})^{11-14}$.

Although officially recognized ${ }^{1}$, the clinical and EEG differences between mesial and lateral TLS are still a matter of controversy ${ }^{15-17}$. We compared the sequential behavior characteristics and EEG features of 50 seizures due to mesial and lateral lesions.

\section{PATIENTS AND METHODS}

We selected 17 refractory TLE patients who underwent pre-surgical evaluation at the Hospital das Clínicas da Faculdade de Medicina da USP. Their seizures were divided in two groups: group 1 - 25 seizures from 9 patients with mesial temporal sclerosis (MTS) and group 2 - 25 seizures recorded from 8 patients with neocortical temporal lesions: tumors $(\mathrm{n}=6)$, neocortical atrophy $(\mathrm{n}=1)$ and cystic process $(\mathrm{n}=1)$.

All seizures were recorded in a split-screen video-EEG system (Telefactor-S 01 and Nihon-Kohden-VY 210BK). Two to four seizures were selected from each patient. We followed the same protocol for testing all the patiens during the events and each seizure was analyzed blindly by 2 reviewers. The TLS origin was determined by the anamnesis, neurological examination, functional methods as interictal and ictal EEG in all patients, using the international 10-20 system for electrodes placement and sphenoidal (in 10 patients) or zygomatic electrodes (in 7); interictal Single Photon Emission Computed Tomography (SPECT) studies were obtained in 10 and ictal SPECT in 7 patients, CT in 15 and all of them had neuropsychological evaluation and MRI. The determination of the EA was also based on the fact that all the patients have been seizure free after temporal lobectomy for the MTS patients, and lesionectomy for the others, during the mean follow-up period of 11 months (range 6-16). These data are summarized in Table 1. The seizure onset was determined by the appearance of the first clinical manifestation. Auras were considered when verbally reported by the patient or in the situations when he was unable to speak but felt the symptoms, pushing the video-EEG system alarm button. Motionless staring corresponded to a change in the attitude or behavior of the patient. Ictal and postictal automatisms were classified by their characteristics. Tonic postural motor activity was considered as unilateral tonic posturing (UTP) and if it was accompanied by a rotational and a dystonic component with a forced unnatural position, as unilateral dystonic posturing (UDP). Unilateral ictal immobility (UII) consisted of a decrease or absence of active movement of one or more members during the seizure. Non-forced head turning (NHT) corresponded to unforced and not maintained movements of the head and eyes while the term forced head turning (FHT) was restricted to the forced and maintained head and eyes deviations. Postictally, we observed orientation and language changes. We considered as inconclusive, the cases which seizure analysis was impaired by postictal adverse conditions, as lethargy, abulia or after the occurrence of secondary generalization.

The methodology for the EEG analysis was based on Walczak et al. ${ }^{14}$ study. For each seizure, the following elements were observed: 1) activity at seizure onset including spikes, sharp waves, desynchronization and irregular paroxysmal activity; 2) rhythmic theta or alpha waves lasting at least 10 seconds and occurring within 40 seconds of EEG seizure onset and 3) postictal findings, including slow waves or attenuation .

\section{RESULTS}

The duration of seizures was in average 53.7 seconds, without differences between the two groups. Auras were observed in $14 \%$ of the seizures. When we considered suggestive manifestations of auras, like a change in the facial expression or behavior, this number rose to $42 \%$. Abdominal auras were the most frequent, with a $100 \%$ incidence in group 1 patients. Motionless staring was observed in 16 seizures (32\%), without differences between groups 1 and 2 . Automatisms were seen in $98 \%$ of the seizures and the oromandibular type was the most frequent. Spitting automatism and 


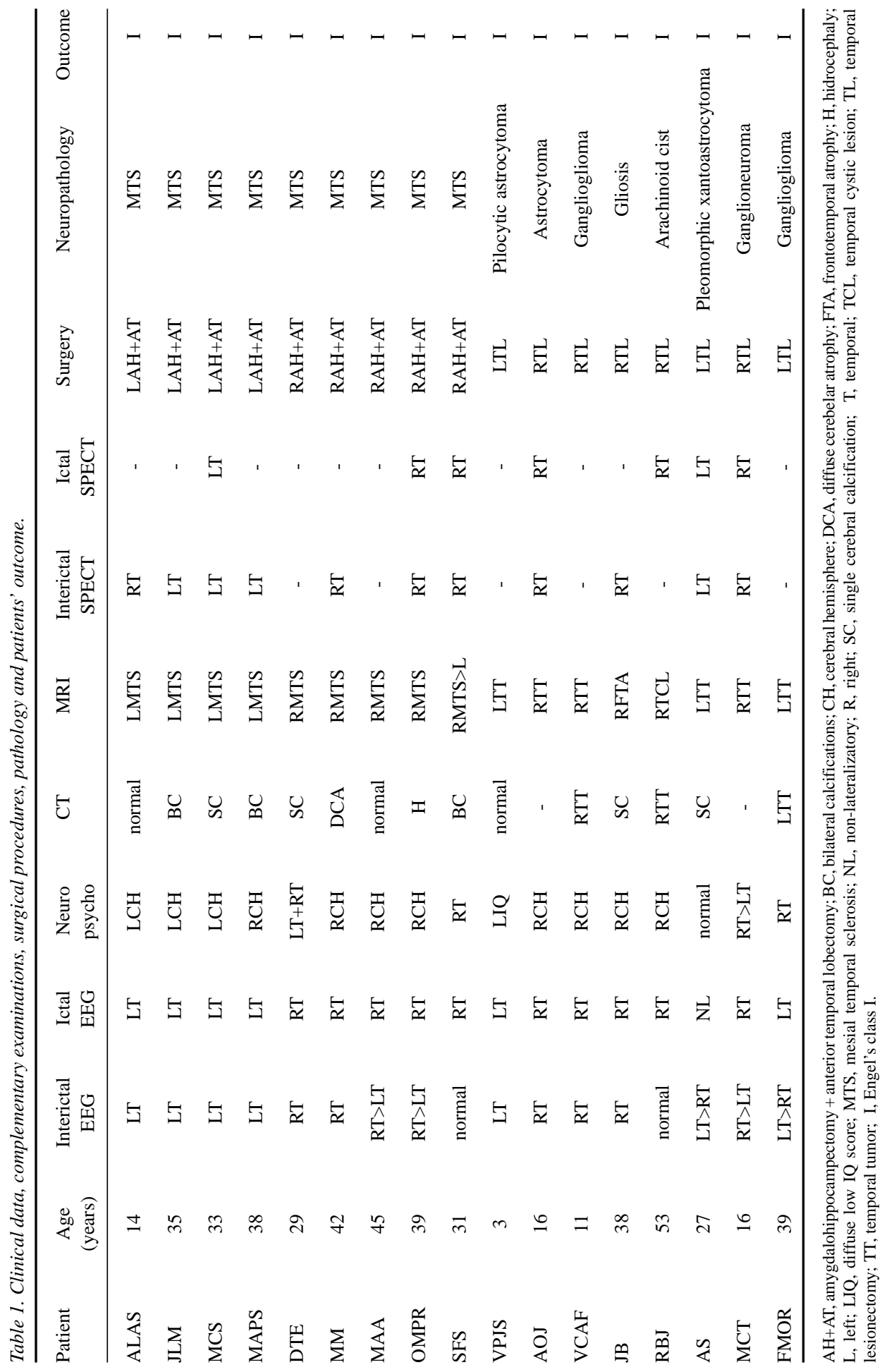



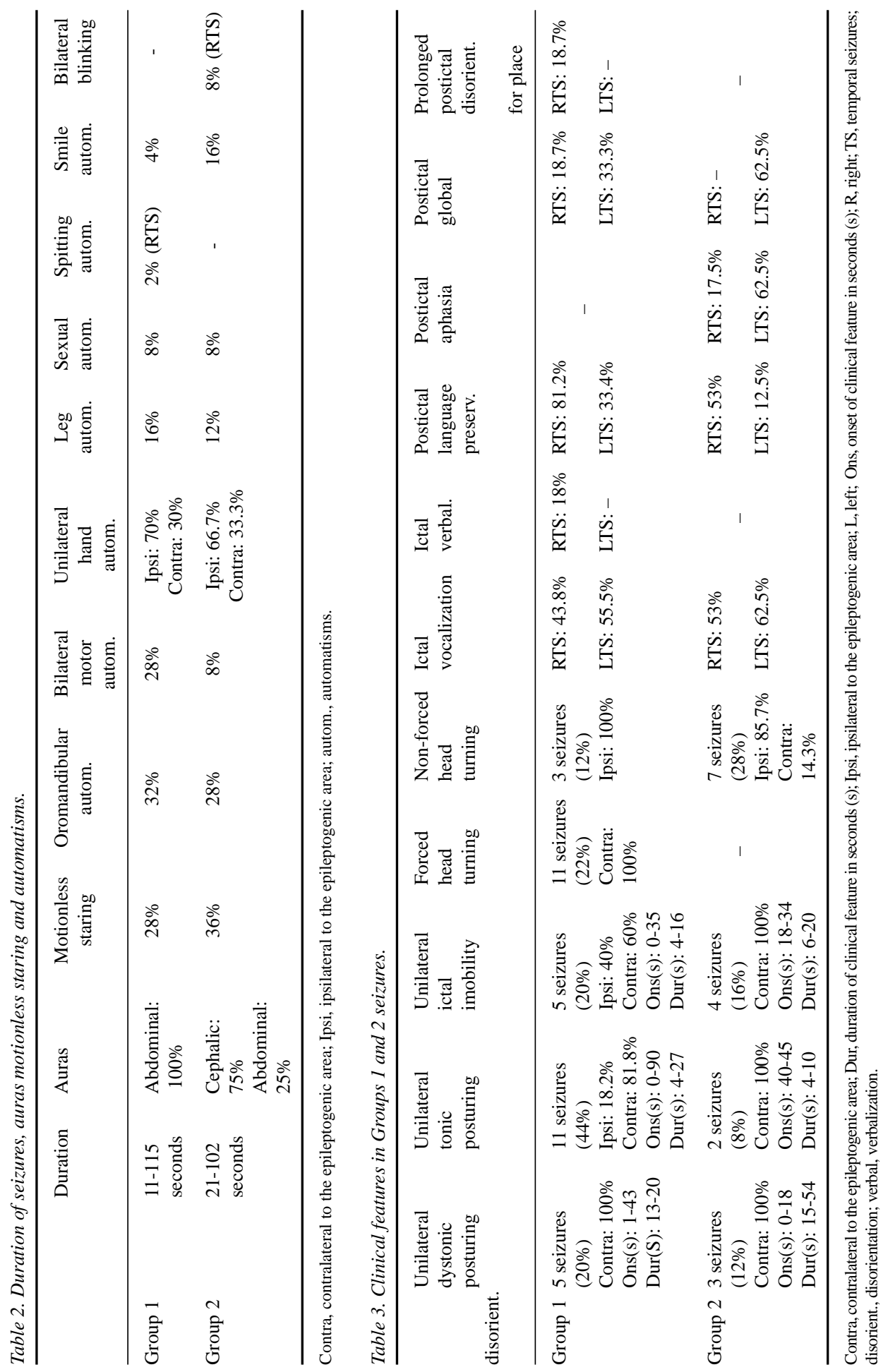
bilateral blinking occurred in right temporal seizures, while other types such as manipulation of genitals or simple and complex motor activities were equally observed in left and right TLS groups. Mimic automatism of smile occurred mainly in neocortical seizures. Unilateral motor automatisms occurred in 19 seizures (38\%), being ipsilateral to the EA in $68.4 \%$. Unilateral upper limb automatisms occurred more frequently in group 1. Leg automatisms occurred in four patients of group 1 and in three patients of group 2; after five seconds of clinical seizure onset, they were more frequent in group 2 patients. These data are sumarized in Table 2 .

UDP was observed in $16 \%$ of seizures, mainly in group 1 patients, being always contralateral to the EA. This feature occurred more precociously and had a longer duration in group 2 seizures. UTP occurred in $26 \%$ of seizures more frequently in group 1 , being contralateral to the EA in $84.6 \%$. UII was observed in $18 \%$ of seizures, contralateral to EA in $77.7 \%$ without differences between the two groups.

FHT was observed in $22 \%$ of group 1 seizures, always contralateral to the EA, while NHT occurred in $20 \%$ of seizures mainly in group 2, being ipsilateral to the EA in $90 \%$.

Ictal speech occurred in $70 \%$ of seizures, being 25 related to the right and ten related to the left TLS. Ictal verbalization was observed in $18 \%$, exclusively in right TLS and in group 1. Memory impairment was observed in almost all seizures. Postictal automatisms were frequently observed in both groups, sometimes similar to the ictal ones. Postictal language was preserved in eight $(88.8 \%)$ of nine right EA patients and in one (25\%) of four of the left EA patients. Postictal aphasia occurred in four patients, three $(75 \%)$ with left and one $(11.1 \%)$ with right temporal seizure origin. Postictal language was more preserved in group 1 patients (mean 57.3\%) than in group 2 (mean 32.7\%). Postictal global disorientation was more frequent in group 1 and in left TLS patients while prolonged postictal disorientation for place was observed in right TLS. These clinical features are sumarized in Table 3.

Interictal EEG evidenced independent bitemporal epileptiform paroxysms in $41.1 \%$ of the patients predominating in the epileptogenic lobe without differences between the two groups. The most frequently observed ictal pattern was sinusoidal sharp waves. The initial ictal findings were correctly lateralizatory in $44 \%$ of seizures, including desynchronization, mainly in group 2 and irregular slow waves (Fig 1), mainly in group 1. Rhythmic theta or alpha waves occurred in $62 \%$ of

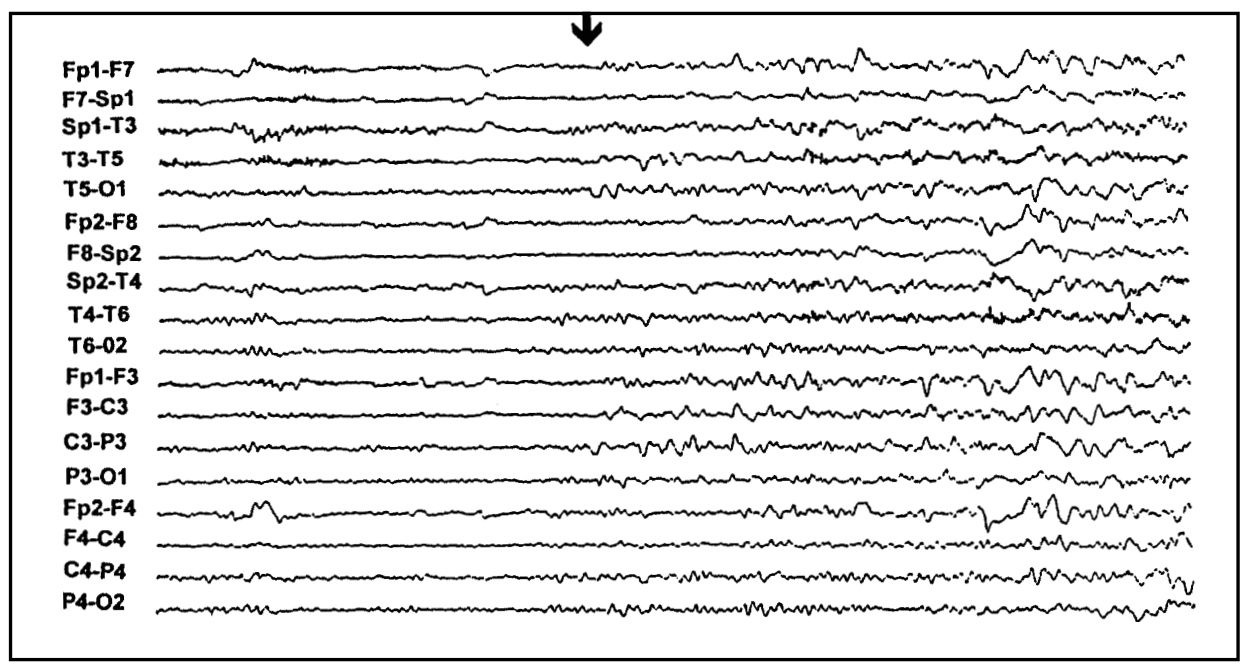

Fig 1. Initial left hemisphere irregular slow waves in a left temporal seizure (arrow). $100 \mu \mathrm{V} / \mathrm{mm}$. 
seizures (Fig 2) being correctly lateralizatory in 54\% and falsely lateralizatory in $8 \%$, without differences between the two groups. Lateralizatory postictal findings included temporal or hemispheric slow waves (Fig 3) and occurred in $48 \%$ of seizures allowing correct lateralization of the EA in $96 \%$.

\section{DISCUSSION}

The duration of TLS in this casuistics is similar to that of others ${ }^{5,9,18}$. The low incidence of auras is also reported by other video-EEG studies ${ }^{9,19}$, and it can be related to some patients' inability to report them after secondarily generalized seizures related to antiepileptic drug reduction with a larger incidence of retrograde amnesia ${ }^{20}$. The significant increase of the aura percentage, when we considered the presence of indicative signs, may suggest the need of their inclusion in video-EEG studies. Other video-EEG studies reported abdominal auras as the most prevalent type ${ }^{9,16}$ mainly in

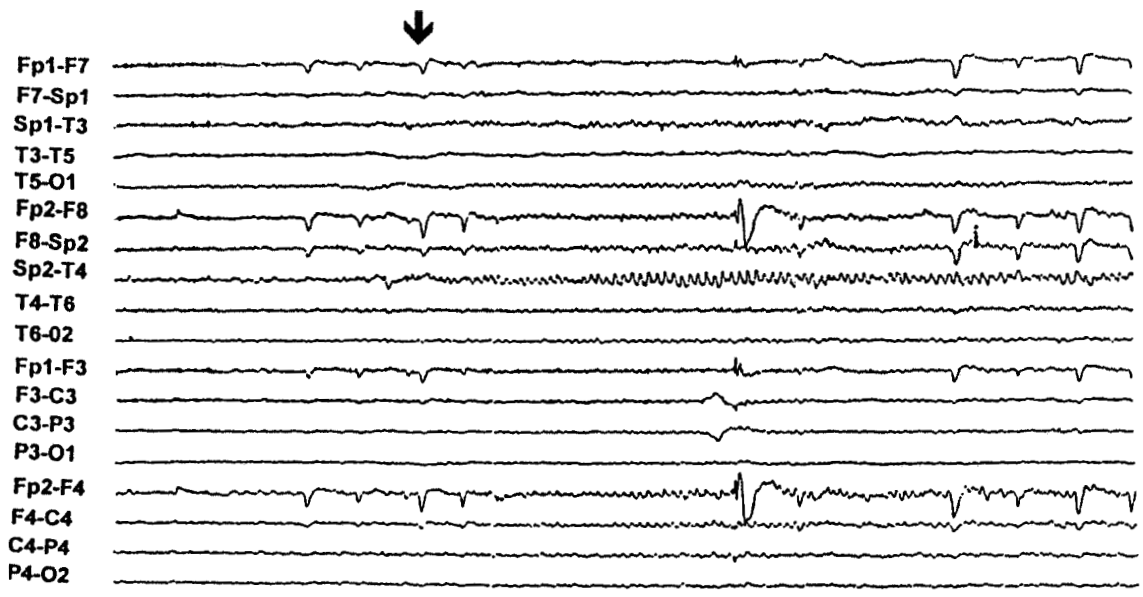

Fig 2. Right temporal rhythmic theta waves during a right temporal seizure (arrow). $100 \mu \mathrm{V} / \mathrm{mm}$.

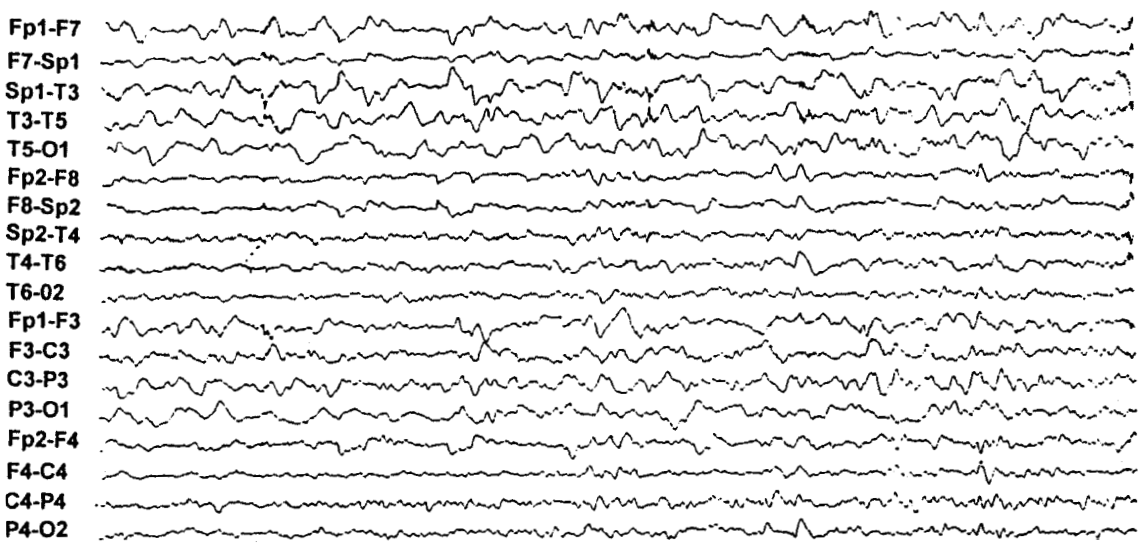

Fig 3. Postictal left hemisphere slow waves after left temporal seizure. $100 \mu \mathrm{V} / \mathrm{mm}$. 
mesial temporal seizures ${ }^{15}$, as we observed in our casuistics. Motionless staring occurred in $32 \%$ similarly to the result observed by Yacubian et al. ${ }^{9}$. There were no differences between the two groups, as in other comparative casuistics ${ }^{15,16}$. Although Berkovic and Bladin ${ }^{21}$ have suggested that this clinical feature may represent only some patients' mental deep concentration during the aura, epileptic discharges spreading toward deep medium cerebral structures, midbrain and posterior comissure seems to be involved ${ }^{22}$.

Similarly to our results, others reported a great percentage of automatisms during TLS, specially the oromandibular type $e^{5,9,16,18}$. There were no differences between the two groups as in the casuistic of O'Brien et al. ${ }^{15}$. Spitting automatism occurred during right temporal seizures as it is found in the literature $^{18}$, representing a lesser common type of oral motor automatism ${ }^{23}$. Sexual automatisms are more related to right temporal seizures ${ }^{24}$, although in our casuistics they were found in left and right TLS. Mimic automatism of smile occurred predominantly in neocortical seizures, a fact reported by Hiyoshi et al. ${ }^{25}$. Unilateral motor automatisms were predominantly ipsilateral to the EA, as occurred in other casuistics ${ }^{26,27}$. The predominance of unilateral upper limb automatisms in group 1 seizures was also found by Saygi et al. ${ }^{16}$, who also reported, as in our study, a larger incidence of leg automatisms after the first five seconds of ictal onset in group 2 patients.

UDP occurred in $16 \%$ of the seizures, a less expressive result to that observed in other studies $^{6,8,9,26}$. This feature was always contralateral to the EA matching with other reports ${ }^{6,8,28,29}$ and confirming its lateralizatory value. Semah et al. ${ }^{27}$, however, observed UDP ipsilateral to the EA in $100 \%$ of the neocortical seizures and contralateral dystonia of $96 \%$ in mesial seizures. UDP seems to result from epileptic discharges spreading toward contralateral basal nuclei ${ }^{8}$, a fact confirmed by ictal SPECT studies ${ }^{30}$. UDP occurred more precociously and had a longer duration in group 2 seizures, a fact not observed in other studies ${ }^{15,16}$.

UTP was observed in $26 \%$ of seizures being contralateral to the EA in most of the cases. In the literature, the lateralizatory value of UTP is controversial ${ }^{6}$, mainly because it may result from extratemporal regions involvement by epileptic discharges ${ }^{8}$. Although it was also observed in the casuistics of Saygi et al. ${ }^{16}$, the predominance of this feature among group 1 seizures may be explained by the presence of secondarily generalized seizures, observed exclusively in this group.

UII was predominantly contralateral to the EA in our study. This feature is considered lateralizatory by some authors ${ }^{9,31}$ and controversial by others ${ }^{6}$. There were no differences between the two groups as reported by O'Brien et al. ${ }^{15}$. Oestreich et al. ${ }^{31}$ suggested that UII may result of contralateral motor area dysfunction provoked by epileptic discharges. For Bleasel et al. ${ }^{6}$ it can be the result of a tonic process without obvious clinical manifestation.

FHT occurred in $22 \%$ of the seizures being always contralateral to the EA, similarly to other studies $^{9,32}$. This feature occurred predominantly in the left temporal seizures as in the casuistics of Fakhoury et al. ${ }^{18}$. The presence of FHT exclusively in group 1 patients was not observed in other casuistics ${ }^{15,16}$. In ours, this fact may be explained by the presence of secondarily generalized seizures only in group 1, with the consequent discharges spreading toward extratemporal regions. NHT was predominantly ipsilateral to the EA. In the literature the lateralizatory value of this feature is controversial $^{32,33}$ since it may result of epileptic discharges spreading toward other regions of the brain $^{30}$.

Ictal speech occurred mainly during right temporal seizures as reported by others ${ }^{18,34}$ suggesting nondominant temporal $\mathrm{EA}^{18,26,35,36}$. It seems to result of functional nondominant temporal lobe impairment by epileptic discharges and consequent hyperfunction of the dominant hemisphere for language ${ }^{35}$. Other studies ${ }^{15,16}$ also did not find any differences on ictal speech between the two groups. The greatest percentage of postictal language preservation in the right temporal EA patients was also observed in other studies ${ }^{7,18}$. Postictal aphasia occurred mainly in the left temporal seizures as in other casuistics ${ }^{7,18,26,35}$. It seems to result of functional impairment of the dominant basal temporal 
lobe language area ${ }^{36}$. The greatest percentage of language preservation in group 1 patients was not observed in other studies ${ }^{15,16}$ and it may be related to the large number of inconclusive seizure analysis, mainly in this group.

Global disorientation was more frequent after left temporal seizures. Although some authors have reported impaired consciousness mainly after dominant hemisphere lesions ${ }^{37}$ and others have reported a rapid return to baseline postictally after right temporal seizures ${ }^{18}$ our results may just be related to postictal language disabilities. Prolonged disorientation for place after right temporal seizures was previously reported ${ }^{7}$ and it may be related to the fact that topographic disorientation and loss of topographic memory are more common after right hemisphere lesions ${ }^{38}$. Postictal orientation was preserved mainly in group 2 seizures, a fact that has not been commented in the literature.

The most observed ictal EEG pattern was sinusoidal sharp waves as reported by Blume et al. ${ }^{39}$. The percentage of correct lateralization based on initial ictal EEG features and rhythmic theta or alpha waves was similar to other studies ${ }^{11,14}$. There were no differences between the two groups for rhythmic waves presence, as reported by Burgerman et al. ${ }^{12}$ although O'Brien et al. ${ }^{15}$ have observed this EEG feature mainly in mesial seizures. False lateralization occurred in one seizure of group 1 and in three temporal tumor patients of group 2, a phenomenon already described ${ }^{40}$. Postictal EEG lateralizatory findings were observed in $48 \%$ of the seizures and they correctly lateralized the EA in almost all of them, as reported by others ${ }^{14,41}$. Although we observed a high percentage of correct lateralization, the presence of postictal features in only about $50 \%$ of seizures in our casuistics limited its value, as was also observed in Walczak et al. ${ }^{14}$ study.

\section{REFERENCES}

1. Commission on Classification and Terminology of the International League Against Epilepsy. Proposal for revised classification of epilepsies and epileptic syndromes. Epilepsia 1989;30:389-399.

2. Manford M, Fish DR, Shorvon SD. An analysis of clinical seizure patterns and their localizing value in frontal and temporal lobe epilepsies. Brain 1996;119:17-40.

3. Annegers JF, Hauser WA, Elverback LR. Remission of seizures and relapse in patients with epilepsy. Epilepsia 1980; 20: 729-737.

4. Wieser HG, Meles HP, Bernoulli C, Siegfried J. Clinical and chronotopographic psychomotor seizure patterns (SEEG study with reference to postoperative results). Acta Neurochir 1980;30(Suppl):103-112.

5. Delgado-Escueta AV, Bacsal FE, Treiman DM. Complex partial seizures on closed-circuit television and EEG: a study of 691 attacks in 79 patients. Ann Neurol 1982;11:292-300.

6. Bleasel A, Kotagal P, Kankirawatana P, Rybicki L. Lateralizing value and semiology of ictal limb posturing and version in temporal lobe and extratemporal epilepsy. Epilepsia 1997;38:168-174.

7. Devinsky O, Kelly K, Yacubian EMT, et al. Postictal behavior: a clinical and subdural electroencephalographic study. Arch Neurol 1994;51:254-259.

8. Kotagal P, Lüders H, Morris HH, et al. Dystonic posturing in complex partial seizures of temporal lobe onset: a new lateralizing sign. Neurology 1989;39:196-201.

9. Yacubian EMT, Valério RMF, Jorge CL, Fiori LA, Cukiert A, Assis LM. Manifestações clínicas de crises parciais complexas do lobo temporal. Arq Neuropsiquiatr 1994;52;137-143.

10. Gibbs FA, Gibbs EL, Lennox WG. Cerebral dysrhythmias of epilepsy. Arch Neurol Psychiatry 1938;39:298-314.

11. Baumgartner C, Pataraia E, Lurger S, et al. Ictal EEG patterns in mesial temporal lobe epilepsy. Epilepsia 1997;38:377.

12. Burgerman RS, Sperling MR, French JA, Saykin AJ, O'Connor MJ. Comparison of mesial versus neocortical onset temporal lobe seizures: neurodiagnostic findings and surgical outcome. Epilepsia 1995;36:662-670.

13. Risinger MW, Engel J, Van Ness PC, Henry TR, Crandall PH. Ictal localization of temporal lobe seizures with scalp/ sphenoidal recordings. Neurology 1989;39:1288-1293.

14. Walczak TS, Radtke RA, Lewis DV. Accuracy and interobserver reliability of scalp ictal EEG. Neurology 1992;42:2279-2285

15. O'Brien TJ, Kilpatrick C, Murrie V, Vogrin S, Morris K, Cook MJ. Temporal lobe epilepsy caused by mesial temporal sclerosis and temporal neocortical lesions: a clinical and electroencephalographic study of 46 pathologically proven cases. Brain 1996;119:2133-2141.

16. Saygi S, Spencer SS, Scheyer R, Katz A, Mattson R, Spencer DD. Differentiation of temporal lobe ictal behavior associated with hippocampal sclerosis and tumors of temporal lobe. Epilepsia 1994;35:737-742.

17. Walczak TS. Neocortical temporal lobe epilepsy: characterizing the syndrome (Editorial). Epilepsia 1995;36:633-635.

18. Fakhoury T, Abou-Khalil B, Peguero E. Differentiating clinical features of right and left temporal lobe seizures. Epilepsia 1994:35:1038-1044. 
19. Kotagal P, Lüders H, Williams G, Wyllie E, Nichols T, McPherson J. Temporal lobe complex partial seizures: analysis of symptom clusters and sequences. Epilepsia 1988;29:661.

20. Palmini A, Gloor P. The localizing value of auras in partial seizures: a prospective and retrospective study. Neurology 1992;42:801-808.

21. Berkovic SF, Bladin PF. An electroclinical study or complex partial seizures. Epilepsia 1984;25:668-669.

22. Escueta AV, Kunze ULF, Waddell G, Boxley J, Nadel A. Lapse of consciousness and automatisms in temporal lobe epilepsy: a videotape analysis. Neurology 1977;27:144-155.

23. Hecker A, Andermann F, Rodin EA. Spitting automatism in temporal lobe epilepsy with a brief review of etiological and phylogenetic aspects of spitting. Epilepsia 1972;13:767-772.

24. Remillard GM, Andermann F, Testa GF, et al. Sexual ictal manifestations predominate in women with temporal lobe epilepsy: a finding suggesting sexual dimorphism in the human brain. Neurology 1983;33:323-330.

25. Hiyoshi T, Seino M, Mihara T, et al. Emotional facial expressions at the onset of temporal lobe seizures: observations on scalp and intracranial EEG recordings. Jpn J Psychiatry Neurol 1989;43:419-426.

26. Chee MW, Kotagal P, Van-Ness PC, Gragg L, Murphy D, Lüders HO. Lateralizing signs in intractable partial epilepsy: blinded multiple-observer analysis. Neurology 1993;43:2519-2525.

27. Semah F, Dupont S, Boon P, et al. Association or unilateral motor automatisms and dystonic posturing in medial vs neocortical temporal lobe epilepsy. Epilepsia 1996;37(Suppl. 5):31.

28. Fakhoury T, Abou-Khalil B. Association of ipsilateral head turning and dystonia in temporal lobe seizures. Epilepsia 1995;36:1965-1970.

29. Jorge CL. Mesial temporal sclerosis epilepsy: clinical and pathophysiological features (Abstract). Arq Neuropsiquiatr 1996;54:532-533.

30. Newton MR, Berkovic SF, Austin MC, Reutens DC, McKay WJ, Bladin PF. Dystonia, clinical lateralization, and regional blood flow changes in temporal lobe seizures. Neurology 1992;42:371-377.

31. Oestreich L, Berg M, Bachmann D, Burchfiel J, Erba G. Ictal contralateral paresis in complex partial seizures. Epilepsia 1995;36:671-675.

32. Wyllie E, Lüders H, Morris HH, Lesser RP, Dinner DS. The lateralizing significance of versive head and eye movements during epileptic seizures. Neurology 1986;36:606-611.

33. McLachlan RS. The significance or head and eye turning in seizures. Neurology 1987;37:1617-1619.

34. Yen DJ, Su MS, Yiu CH, et al. Ictal speech manifestations in temporal lobe epilepsy: a video-EEG study. Epilepsia 1996;37:45-49

35. Gabr M, Lüders H, Dinner D, Morris H, Wyllie E. Speech manifestations in lateralization of temporal lobe seizures. Ann Neurol 1989;25:82-87.

36. Lüders H, Lesser RP, Hahn J, et al. Basal temporal language area. Brain 1991;114:743-754

37. Albert M, Silverberg R, Reches A, Berman M. Cerebral dominance for consciousness. Arch Neurol 1976;33:453-454.

38. Fischer CM. Topographical disorientation. Arch Neurol 1982;39:33-36.

39. Blume W, Young GB, Lemieux JF. EEG morphology of partial epileptic seizures. Electroencephalogr Clin Neurophysiol 1984;57:295-302.

40. Sammaritano M, Lotbinière A, Andermann F, Olivier A, Gloor P, Quesney LF. False lateralization by surface EEG of seizure onset in patients with temporal lobe epilepsy and gross focal cerebral lesions. Ann Neurol 1987;21:361-369.

41. Kaibara M, Blume WT. The postictal electroencephalogram. Electroencephalogr Clin Neurophysiol 1988;70:99-104. 